\title{
Impact of subclinical coronary artery disease on the clinical outcomes of carotid endarterectomy
}

\author{
Hyunwook Kwon, MD, ${ }^{1}$ Dae Hyuk Moon, MD, PhD, ${ }^{2}$ Youngjin Han, MD, ${ }^{1}$ Jong-Young Lee, MD, PhD, ${ }^{3}$ \\ Sun U Kwon, MD, PhD, ${ }^{4}$ Dong-Wha Kang, MD, PhD, ${ }^{4}$ Suk Jung Choo, MD, PhD, ${ }^{5}$ \\ Tae-Won Kwon, MD, PhD, ${ }^{1}$ Min-Ju Kim, MSc, ${ }^{6}$ and Yong-Pil Cho, MD, PhD ${ }^{1}$
}

\begin{abstract}
Departments of ${ }^{1}$ Surgery, ${ }^{2}$ Nuclear Medicine, ${ }^{4}$ Neurology, and ${ }^{5}$ Thoracic Surgery, and ${ }^{6}$ Biostatistics Collaboration Unit, University of Ulsan College of Medicine and Asan Medical Center, Seoul, Korea; and ${ }^{3}$ Department of Internal Medicine, Kangbuk Samsung Hospital, Sungkyunkwan University School of Medicine, Seoul, Korea
\end{abstract}

\begin{abstract}
OBJECTIVE Controversy persists regarding the optimal management of subclinical coronary artery disease (CAD) prior to carotid endarterectomy (CEA) and the impact of CAD on clinical outcomes after CEA. This study aimed to evaluate the short-term surgical risks and long-term outcomes of patients with subclinical CAD who underwent CEA.

METHODS The authors performed a retrospective study of data from a prospective CEA registry. They analyzed a total of 702 cases involving patients without a history of CAD who received preoperative cardiac risk assessment by radionuclide myocardial perfusion imaging (MPI) and underwent CEA over a 10-year period. The management strategy (the necessity, sequence, and treatment modality of coronary revascularization and optimal perioperative medical treatment) was determined according to the presence, severity, and extent of CAD as determined by preoperative MPI and additional coronary computed tomography angiography and/or coronary angiography. Perioperative cardiac damage was defined on the basis of postoperative elevation of the blood level of cardiac troponin I (0.05-0.5 ng/ml) in the absence of myocardial ischemia. The primary endpoint was the composite of any stroke, myocardial infarction, or death during the perioperative period and all-cause mortality within 4 years of CEA. The associations between clinical outcomes after CEA and subclinical CAD were analyzed.
\end{abstract}

RESULTS Concomitant subclinical CAD was observed in 81 patients (11.5\%). These patients did have a higher incidence of perioperative cardiac damage $(13.6 \%$ vs $0.5 \%, p<0.01)$, but they had similar primary endpoint incidences during the perioperative period ( $2.5 \%$ vs. $1.8 \%, p=0.65)$ and similar estimated 4-year primary endpoint rates $(13.6 \%$ vs $12.4 \%, p=0.76$ ) as the patients without subclinical CAD. Kaplan-Meier survival analysis showed that the 2 groups had similar rates of overall survival $(p=0.75)$.

CONCLUSIONS Patients with subclinical CAD can undergo CEA with acceptable short- and long-term outcomes provided they receive selective coronary revascularization and optimal perioperative medical treatment.

https://thejns.org/doi/abs/10.3171/2016.3.JNS16287

KEY WORDS carotid artery; carotid stenosis; coronary artery; endarterectomy; myocardial infarction; outcome; vascular disorders

I $\mathrm{T}$ is well known that carotid endarterectomy (CEA) is a reliable procedure for preventing recurrent neurological symptoms and stroke in patients with significant carotid artery stenosis. ${ }^{8,20}$ However, life expectancy and operative risk are important factors in evaluating the benefits of CEA due to its preventive nature, and clinical guidelines indicate the upper acceptable limits of morbidity and mortality for performing this operation. ${ }^{5,19}$ Cardiac events are an important cause of morbidity and mortality after CEA..$^{917,21,25}$ Hence, in these cases, preoperative car- diac evaluation could be used when deciding whether to perform CEA or manage conservatively, despite the limitations of preoperative evaluation in predicting perioperative cardiac complications and survival. ${ }^{17,22}$ The simultaneous presence of significant carotid artery disease and other cardiac risks makes it difficult to determine the optimal management strategy. $1,5,9,13,17,19,21,22$ Thus, controversy persists regarding the optimal management of subclinical coronary artery disease (CAD) prior to CEA and its impact on clinical outcomes after CEA. ${ }^{11-13,18}$

ABBREVIATIONS CABG = coronary artery bypass graft; $C A D=$ coronary artery disease; $C A G=$ coronary angiography; $C E A=$ carotid endarterectomy; $C T A=C T$ angiography; $\mathrm{MPI}=$ myocardial perfusion imaging; $\mathrm{PCI}=$ percutaneous coronary intervention.

SUBMITTED February 3, 2016. ACCEPTED March 31, 2016.

INCLUDE WHEN CITING Published online June 3, 2016; DOI: 10.3171/2016.3.JNS16287. 
The aim of this single-center study was to analyze the short-term operative risks and long-term outcomes of patients with subclinical CAD who underwent CEA based on our management strategy (necessity, sequence and treatment modality of coronary revascularization, and optimal perioperative medical treatment). The management strategy was determined according to the presence, severity, and extent of CAD diagnosed by preoperative radionuclide adenosine stress myocardial perfusion imaging (MPI) and additional coronary CT angiography (CTA) and/or coronary angiography (CAG).

\section{Methods}

This study was a retrospective analysis of data from the prospective CEA registry of Asan Medical Center. The protocol was approved by the institutional review board of that institution.

Between January 2005 and December 2014, 846 patients who had significant carotid bifurcation stenosis (i.e., $\geq 70 \%$ in asymptomatic patients and $\geq 50 \%$ in symptomatic patients) underwent CEA as defined by criteria established by the North American Symptomatic Carotid Endarterectomy Trial (NASCET). ${ }^{20}$ Patients with a medical history of CAD (144 patients, $17.0 \%$ ) were excluded from the present analysis (Fig. 1). The remaining 702 patients constituted the study group for this study. Of those patients, 81 were found to have subclinical CAD during preoperative evaluation (see below) and 621 were found to have no evidence of CAD.

Management strategies were determined according to the presence, severity, and extent of CAD diagnosed by preoperative radionuclide MPI. Thallium-201 singlephoton emission computed tomography (SPECT) was the default stress MPI modality during the study period. Relative perfusion distributions were analyzed in 17 myocardial segments as described previously. ${ }^{16}$ SPECT results were considered to be abnormal if the summed stress score was 3 or greater. A score of 7 or greater (equivalent to more than $10 \%$ abnormal myocardium) was regarded as indicating a moderate to large amount of myocardial ischemia. ${ }^{3}$ In patients with fixed perfusion defects or small perfusion defects, CEA was performed without any additional cardiac risk assessment. In cases with moderate to large perfusion defects, additional coronary CTA and/or CAG was performed to determine whether coronary revascularization should be performed before or after CEA and whether coronary revascularization should be achieved by coronary artery bypass graft $(\mathrm{CABG})$ or percutaneous coronary intervention (PCI). In patients requiring PCI, staged PCI was performed, followed by CEA with dual antiplatelet therapy. In those requiring $\mathrm{CABG}$, staged $\mathrm{CEA}$ was performed, followed by CABG with aspirin treatment. In those requiring urgent $\mathrm{CEA}$ for symptomatic, severe carotid artery stenosis, staged CEA was performed, followed by coronary revascularization.

Independent neurological evaluation using the National Institutes of Health Stroke Scale ${ }^{4}$ and the modified Rankin Scale was performed at baseline, 6-8 hours after CEA, as well as at discharge, 6 and 12 months after CEA, and an-

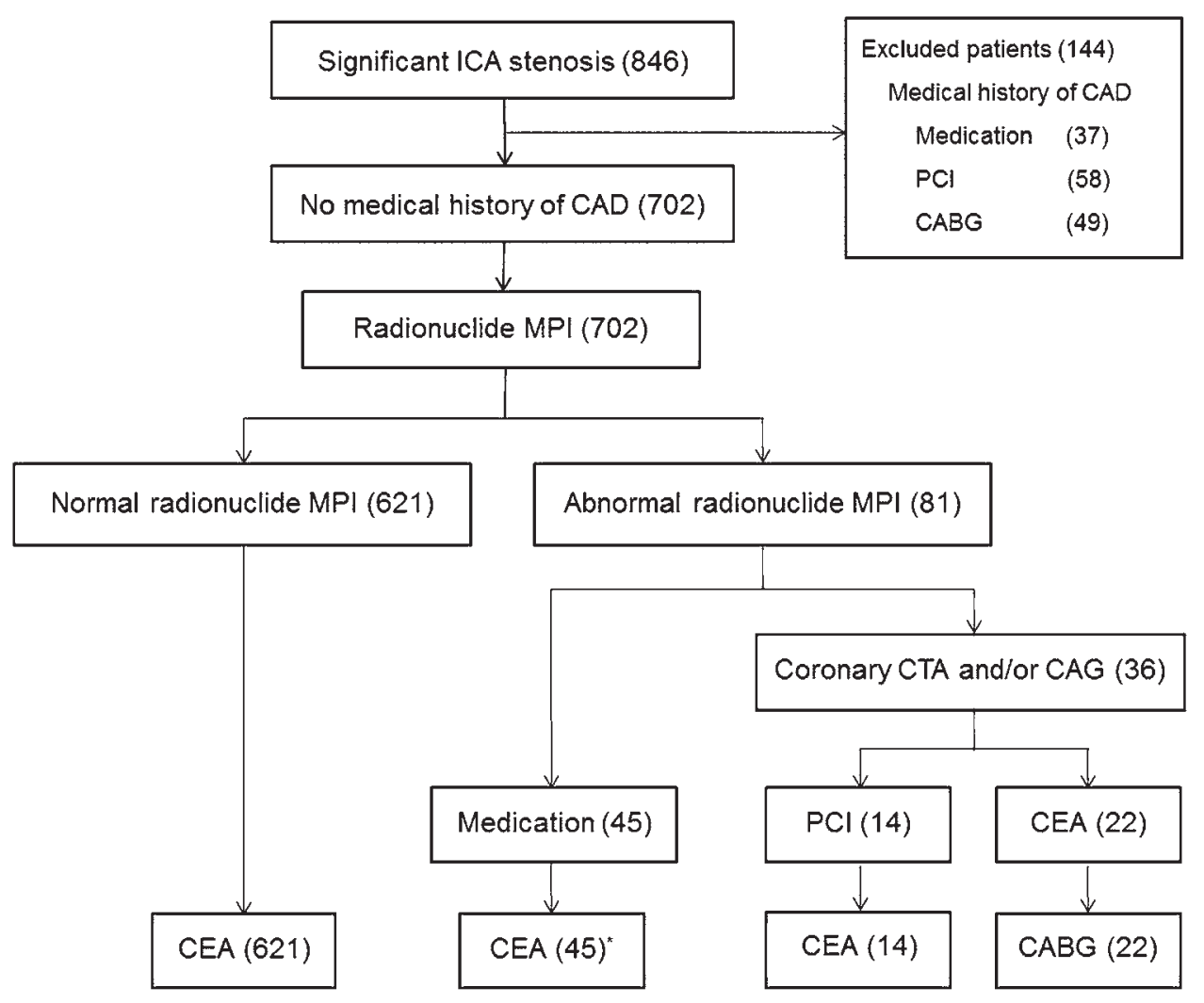

FIG. 1. Flowchart of patient inclusion and management protocol. Values in parentheses are numbers of patients. *Two patients who required urgent $\mathrm{CEA}$ received staged CEA followed by $\mathrm{PCI}$. ICA = internal carotid artery. 
nually thereafter. Cardiac enzyme level measurements and electrocardiography were performed at baseline before CEA, 6-8 hours after CEA, and 48 hours after CEA. Carotid duplex ultrasonography was performed before CEA, 6 and 12 months after CEA, and annually thereafter. Once stability was established over the course of 3 years, surveillance was performed at approximately 2 -year intervals.

Risk factors of interest, clinical characteristics, and clinical outcomes for all patients were recorded in an Excel database (Microsoft Corp.) and analyzed retrospectively. Postoperative stroke was defined as an acute neurological event with symptoms of focal cerebral ischemia lasting 24 hours or more. ${ }^{6}$ Cardiac damage was defined as postoperative elevation of the blood concentration of cardiac troponin I $(0.05-0.5 \mathrm{ng} / \mathrm{ml})$ in the absence of myocardial ischemia. ${ }^{10}$ Myocardial infarction was defined as a postoperative cardiac troponin I level $>0.5 \mathrm{ng} / \mathrm{ml}$ with chest pain, ischemia symptoms, or electrocardiographic evidence of ischemia, such as a new ST-segment depression or ST-segment elevation $\geq 1 \mathrm{~mm}$ in 2 or more contiguous leads. ${ }^{6}$ The primary endpoints were 1) the composite of any stroke, myocardial infarction, or death during the perioperative period and 2) all-cause mortality within 4 years of CEA.

Numerical demographic and clinical characteristics were analyzed by chi-square and Fisher exact tests, as appropriate. Continuous variables in the form of means \pm standard deviations were compared by Student t-test. Logistic regression analysis was used to evaluate risk factors for cardiac damage following CEA. Variables that were significant at $\mathrm{p}<0.2$ in univariate analysis were incorporated into a multivariate logistic regression model. Overall survival rates were calculated by the Kaplan-Meier method and compared using the log-rank test. All statistical analyses were carried out with SPSS software (version 18.0; SPSS, Inc.), and $\mathrm{p} \leq$ 0.05 was considered statistically significant.

\section{Results}

Of 702 patients without a medical history of CAD, 81 (11.5\%) had abnormal preoperative radionuclide MPI findings (Fig. 1). After we assessed the severity and extent of CAD, 45 patients $(55.6 \%)$ with fixed perfusion defects or small myocardial ischemia received CEA without any additional cardiac risk assessment or coronary revascularization. The remaining 36 patients $(44.4 \%)$ with moderate to large myocardial ischemia were considered for elective coronary revascularization. Additional coronary CTA or CAG indicated 1-, 2-, or 3-vessel disease in 9 (25.0\%), 8 (22.2\%), and $19(52.8 \%)$ of these patients, respectively. Fourteen patients (17.3\%) were treated with staged PCI followed by CEA (mean interval 19 days). Twenty-two patients (27.2\%) were treated with staged CEA followed by CABG (mean interval 44 days). All PCI/CEA patients received dual antiplatelet therapy after PCI, and all CEA/CABG patients received aspirin treatment after CEA. Two patients $(2.5 \%)$ who required urgent CEA for symptomatic, severe carotid artery stenosis received staged CEA followed by PCI with dual antiplatelet therapy (mean interval from CEA to PCI 10.5 days).

Analysis of demographic characteristics, risk factors, and clinical characteristics indicated that patients with subclinical CAD were more likely to be male $(p=0.04)$ and to have diabetes mellitus ( $\mathrm{p}<0.01)$ and chronic kidney disease $(p=0.02)$ (Table 1). They did not otherwise differ significantly from patients without subclinical CAD. There was no significant difference in the incidence of postoperative bleeding complications between patients with and without subclinical CAD ( $2.5 \%$ vs $1.4 \%, \mathrm{p}=0.36)$, although optimal perioperative medical treatment was continued in patients with subclinical CAD according to our management strategy. Patients with and without subclinical CAD did differ in the incidence of perioperative cardiac damage $(13.6 \%$ vs $0.5 \%, \mathrm{p}<0.01)$, but they did not differ significantly in primary endpoint incidence during the perioperative period $(2.5 \%$ vs $1.8 \%, \mathrm{p}=0.65)$ or in the estimated 4-year primary endpoint rate $(13.6 \%$ vs $12.4 \%$, $\mathrm{p}=0.76$ ) (Table 1). There were no statistically significant differences between the 2 groups in any of the individual components of the primary endpoint. When patients were

TABLE 1. Demographic and clinical characteristics and outcomes*

\begin{tabular}{|c|c|c|c|c|}
\hline Characteristic & Total & No CAD & $\begin{array}{c}\text { Subclinical } \\
\text { CAD }\end{array}$ & $\begin{array}{c}p \\
\text { Value }\end{array}$ \\
\hline No. of patients & 702 & $621(88.5)$ & $81(11.5)$ & \\
\hline Mean age (yrs) & $68.7 \pm 7.9$ & $68.6 \pm 7.9$ & $69.1 \pm 7.5$ & 0.56 \\
\hline Male sex & $607(86.5)$ & $531(85.5)$ & $76(93.8)$ & 0.04 \\
\hline BMI $\left(\mathrm{kg} / \mathrm{m}^{2}\right)$ & $23.9 \pm 2.9$ & $23.8 \pm 2.9$ & $24.4 \pm 3.1$ & 0.09 \\
\hline \multicolumn{5}{|l|}{ Risk factor } \\
\hline DM & $262(37.3)$ & $219(35.3)$ & $43(53.1)$ & $<0.01$ \\
\hline Hypertension & $524(74.6)$ & $461(74.2)$ & $63(77.8)$ & 0.49 \\
\hline Smoking & $447(63.7)$ & $398(64.1)$ & $49(60.5)$ & 0.52 \\
\hline CKD & $62(8.8)$ & $49(7.9)$ & $13(16.0)$ & 0.02 \\
\hline PAOD & $53(7.5)$ & $45(7.2)$ & $8(9.9)$ & 0.39 \\
\hline \multicolumn{5}{|l|}{ Carotid stenosis } \\
\hline Left side & $373(53.1)$ & $326(52.5)$ & $47(58.0)$ & 0.34 \\
\hline Symptomatic & $384(54.7)$ & $341(54.9)$ & $43(53.1)$ & 0.75 \\
\hline Antiplatelet therapy $\dagger$ & $386(55.0)$ & $335(53.9)$ & $51(63.0)$ & 0.12 \\
\hline General anesthesia & $396(56.4)$ & $347(55.9)$ & $49(60.5)$ & 0.43 \\
\hline \multicolumn{5}{|l|}{ Time interval } \\
\hline $\mathrm{PCl}$ to CEA (days) & NA & NA & $18.8 \pm 23.6$ & NA \\
\hline CEA to CABG (days) & NA & NA & $43.7 \pm 59.4$ & NA \\
\hline Bleeding complication & $11(1.6)$ & $9(1.4)$ & $2(2.5)$ & 0.36 \\
\hline Cardiac damage & $14(2.0)$ & $3(0.5)$ & $11(13.6)$ & $<0.01$ \\
\hline Primary endpoint & $13(1.9)$ & $11(1.8)$ & $2(2.5)$ & 0.65 \\
\hline Any stroke & $9 \S(1.3)$ & $9 \S(1.4)$ & $0(0.0)$ & 0.61 \\
\hline Myocardial infarction & $1(0.1)$ & $0(0.0)$ & $1(1.2)$ & 0.11 \\
\hline Death & $4 \S(0.6)$ & $3 \S(0.5)$ & $1(1.2)$ & 0.38 \\
\hline All-cause mortality & $88(12.5)$ & 77 (12.4) & $11(13.6)$ & 0.76 \\
\hline \multicolumn{5}{|c|}{$\begin{array}{l}\mathrm{BMI}=\text { body mass index; } \mathrm{CABG}=\text { coronary artery bypass graft; } \mathrm{CEA}=\text { carotid } \\
\text { endarterectomy; } \mathrm{CKD}=\text { chronic kidney disease; } \mathrm{DM}=\text { diabetes mellitus; } \mathrm{NA}= \\
\text { not applicable; } \mathrm{PAOD}=\text { peripheral arterial occlusive disease; } \mathrm{PCI}=\text { percutane- } \\
\text { ous coronary intervention. } \\
\text { * Values are number of patients }(\%) \text { unless otherwise indicated. } \\
\text { † Previous use of antiplatelet agents regardless of CEA/coronary revascular- } \\
\text { ization. } \\
\text { † Primary endpoint during the perioperative period. } \\
\S \text { One stroke followed by death. } \\
\text { ๆ All-cause mortality within } 4 \text { years of CEA. }\end{array}$} \\
\hline
\end{tabular}


stratified by the severity and extent of CAD, no statistically significant differences were noted with respect to demographic characteristics, clinical characteristics, or clinical outcomes, although there was a trend toward an increased incidence of diabetes mellitus $(p=0.08)$ and cardiac damage $(\mathrm{p}=0.05)$ without statistical significance in patients with moderate to large perfusion defects (Table 2). Of the 45 patients with fixed perfusion defects or small perfusion defects undergoing CEA without coronary revascularization, 5 (11.1\%) received PCI during the follow-up period (mean interval from CEA to PCI 16 months; range 3-40 months). Despite the higher incidence of perioperative cardiac damage in patients with subclinical CAD, KaplanMeier survival analysis showed that the 2 groups had similar rates of overall survival $(p=0.75)$ (Fig. 2). Subclinical CAD was the only risk factor significantly associated with perioperative cardiac damage by univariate $(\mathrm{p}<0.01)$ and multivariate $(\mathrm{p}<0.01)$ analyses (Table 3$)$.

\section{Discussion}

In the present study there was a substantial frequency of subclinical CAD in patients undergoing CEA, with significant carotid artery stenosis in the absence of a medical history of CAD. Our management strategy for patients with both significant carotid artery stenosis and subclinical CAD was determined by 1) the urgency of the carotid artery stenosis and 2) the presence, severity, and extent of CAD diagnosed by preoperative radionuclide MPI and additional coronary CTA and/or CAG. With selective coronary revascularization and perioperative optimal medical treatment, we found that subclinical CAD was not associated with an increased risk of stroke, myocardial infarction, or death during the perioperative period or with all-cause mortality within 4 years of CEA. Although the incidence of perioperative cardiac damage was higher in patients with subclinical CAD, it did not affect all-cause mortality within 4 years of CEA. Therefore, patients with subclinical CAD can undergo CEA with acceptable short- and long-term outcomes provided they receive selective coronary revascularization and optimal perioperative medical treatment.

Preoperative cardiac evaluation is performed in order to lower perioperative morbidity and mortality. ${ }^{22}$ Randomized clinical trials have established the efficacy of CEA for patients with significant carotid artery stenosis. ${ }^{8,20}$ However, in certain prophylactic interventions, life expectancy and operative risk are important factors in evaluating the benefits of surgical intervention. In these cases, cardiac evaluations should be used when deciding whether to perform a CEA or manage the patient's condition conservatively, despite the limitations of these evaluations in predicting perioperative cardiac complications and survival. ${ }^{17,25}$ In the present study, radionuclide adenosine stress MPI was used for preoperative cardiac risk assessment in patients without a medical history of CAD undergoing CEA. The role of radionuclide MPI in preoperative risk stratification in patients undergoing major noncardiac surgery is well established. ${ }^{2,7,14,22,25}$ In addition, the prognostic value of an ischemic myocardium has been investigated in a meta-analysis of patients undergoing vascular surgery: the 30-day cardiac death or nonfatal myocardial infarction rates were $1 \%$ in
TABLE 2. Demographic and clinical characteristics and outcomes according to the severity and extent of CAD*

\begin{tabular}{|c|c|c|c|c|}
\hline \multirow[b]{2}{*}{ Characteristic } & \multirow[b]{2}{*}{ Total } & \multicolumn{2}{|c|}{ Perfusion Defect } & \multirow[b]{2}{*}{$\begin{array}{c}p \\
\text { Value }\end{array}$} \\
\hline & & Small & $\begin{array}{l}\text { Moderate } \\
\text { to Large }\end{array}$ & \\
\hline No. of patients & 81 & $45(55.6)$ & $36(44.4)$ & \\
\hline Mean age (yrs) & $69.1 \pm 7.5$ & $69.8 \pm 6.4$ & $68.1 \pm 8.7$ & 0.28 \\
\hline Male sex & $76(93.8)$ & $42(93.3)$ & $34(94.4)$ & 1.00 \\
\hline $\mathrm{BMI}\left(\mathrm{kg} / \mathrm{m}^{2}\right)$ & $24.4 \pm 3.1$ & $24.3 \pm 3.4$ & $24.5 \pm 2.9$ & 0.71 \\
\hline \multicolumn{5}{|l|}{ Risk factor } \\
\hline DM & $43(53.1)$ & $20(44.4)$ & $23(63.9)$ & 0.08 \\
\hline Hypertension & $63(77.8)$ & $37(82.2)$ & $26(72.2)$ & 0.28 \\
\hline Smoking & $49(60.5)$ & $26(57.8)$ & $23(63.9)$ & 0.57 \\
\hline CKD & $13(16.0)$ & $8(17.8)$ & $5(13.9)$ & 0.63 \\
\hline PAOD & $8(9.9)$ & $4(8.9)$ & $4(11.1)$ & 1.00 \\
\hline \multicolumn{5}{|l|}{ Carotid stenosis } \\
\hline Left side & $47(58.0)$ & $26(57.8)$ & $21(58.3)$ & 0.96 \\
\hline Symptomatic & $43(53.1)$ & $23(51.1)$ & $20(55.6)$ & 0.69 \\
\hline Antiplatelet therapy $\dagger$ & $51(63.0)$ & $28(62.2)$ & $23(63.9)$ & 0.87 \\
\hline General anesthesia & $49(60.5)$ & $28(62.2)$ & $21(58.3)$ & 0.72 \\
\hline Bleeding complication & $2(2.5)$ & $2(4.4)$ & $0(0.0)$ & 0.50 \\
\hline Cardiac damage & $11(13.6)$ & $3(6.7)$ & $8(22.2)$ & 0.05 \\
\hline Primary endpoint & $2(2.5)$ & $0(0.0)$ & $2(5.6)$ & 0.19 \\
\hline Any stroke & $0(0.0)$ & $0(0.0)$ & $0(0.0)$ & NA \\
\hline Myocardial infarction & $1(1.2)$ & $0(0.0)$ & $1(2.8)$ & 0.44 \\
\hline Death & $1(1.2)$ & $0(0.0)$ & $1(2.8)$ & 0.44 \\
\hline All-cause mortality§ & $11(13.6)$ & $5(11.1)$ & $6(16.7)$ & 0.50 \\
\hline
\end{tabular}

* Values are number of patients (\%) unless otherwise indicated.

$\dagger$ Previous use of antiplatelet agents regardless of CEA/coronary revascularization.

$\ddagger$ Primary endpoint during the perioperative period.

$\S$ All-cause mortality within 4 years of CEA.

patients with normal test results, $7 \%$ in patients with fixed defects, and $9 \%$ in those with reversible defects on radionuclide MPI. ${ }^{23}$ Because of the high sensitivity of stress MPI for detecting ischemic heart disease, patients with a normal scan have an excellent prognosis while those with more extensive reversible defects are at increased risk. ${ }^{17}$ Stress caused by surgery and anesthesia may trigger ischemia through an increase in myocardial oxygen demand and/or a reduction in myocardial oxygen supply. Although the roles of routine, prophylactic, and invasive coronary diagnostic evaluation and revascularization in reducing coronary risk for major noncardiac surgery are poorly defined, patients with extensive stress-induced ischemia represent a highrisk population in whom standard medical therapy appears insufficient to prevent perioperative cardiac events. Thus, myocardial revascularization may be recommended before elective noncardiac surgery in patients with evidence of extensive myocardial ischemia. ${ }^{15}$

Cardiac troponin I, a component of the myocardial cell contractile apparatus, is the preferred biomarker for the diagnosis of myocardial infarction because it has high tissue specificity and clinical sensitivity. ${ }^{24}$ Current evidence suggests that even a small increase in the blood level of 


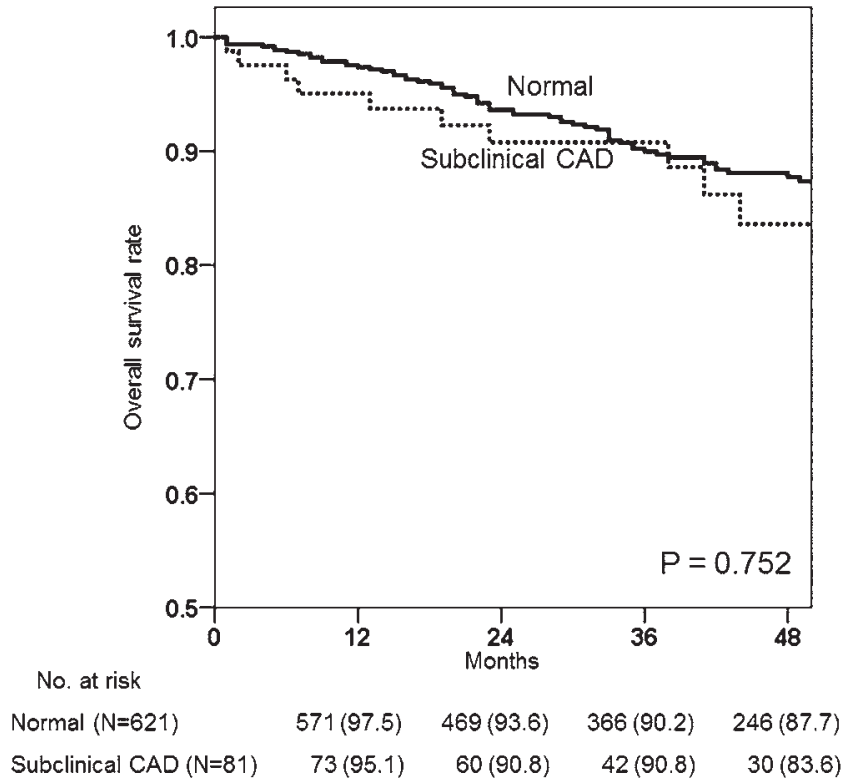

FIG. 2. Kaplan-Meier survival analysis. Overall survival rates of patients with and without subclinical CAD. Values are numbers of patients (\%).

cardiac troponin I in the perioperative period reflects clinically relevant myocardial injury with impaired cardiac prognosis. ${ }^{24}$ In the present study, the incidence of perioperative cardiac damage was significantly higher in patients with subclinical CAD, but this did not affect allcause mortality within 4 years of CEA. During the followup period, risk factor elimination and selective coronary revascularization based on regular surveillance of cardiac risks could result in improved cardiac outcomes compared with other studies.

Patients with both significant carotid artery stenosis and $\mathrm{CAD}$ who are being considered for carotid and/or coronary revascularization should receive optimal medical treatment throughout the perioperative period to reduce the risk of perioperative morbidity and mortality from cardiac events and stroke. To lower the risk of bleeding and thrombosis, elective major noncardiac surgery should be delayed until completion of the full course of recommended dual antiplatelet therapy (ideally 6 months in stable CAD and 1 year in acute coronary syndrome), and performed with continued aspirin treatment. ${ }^{17}$ However, in patients with significant symptomatic carotid artery stenosis, this delay is not advisable; in these patients, it is recommended that CEA be performed within 2 weeks of the last symptoms. ${ }^{1,13,22}$ The sequence of carotid and coronary revascularization and perioperative optimal medical treatment is critical and depends on the clinical presentation; also, the type of coronary revascularization depends on the severity and extent of CAD and the technical feasibility. In the present study, the sequence and type of coronary revascularization was determined based on our management strategy, and optimal medical treatment was continued in patients with subclinical CAD throughout the perioperative period to achieve an equivalent clinical outcome to that achieved in patients without subclinical CAD.

Several limitations of the current study should be noted. It had a retrospective design, which did not allow for direct, randomized comparisons of the treatment outcomes with other therapeutic strategies. In addition, there was no adjustment for baseline differences between patients with and without subclinical CAD. Finally, our current findings were obtained at a single center, and led to a small sample size that limits the overall relevance of our results.

\section{Conclusions}

Our findings indicate that with selective coronary revascularization and perioperative optimal medical treatment, patients with and without subclinical CAD have similar perioperative morbidity, mortality, and long-term survival rates; also perioperative cardiac damage does not affect all-cause mortality within 4 years of CEA. Future prospective trials with larger cohorts should lead to a bet-

TABLE 3. Factors associated with risk of cardiac damage

\begin{tabular}{lccccc}
\hline \multirow{2}{*}{ Risk Factor } & \multicolumn{2}{c}{ Univariate Analysis } & & \multicolumn{2}{c}{ Multivariate Analysis } \\
\cline { 2 - 3 } \cline { 5 - 6 } Age & OR $(95 \% \mathrm{Cl})$ & $\mathrm{p} \mathrm{Value}$ & & $\mathrm{OR}(95 \% \mathrm{Cl})$ & $\mathrm{p} \mathrm{Value}$ \\
\hline Male sex & $1.01(0.93-1.07)$ & 0.93 & & $\mathrm{NA}$ & $\mathrm{NA}$ \\
\hline BMI $\left(\mathrm{kg} / \mathrm{m}^{2}\right)$ & $3.81(0.00-\mathrm{NA})$ & 0.99 & & $\mathrm{NA}$ & $\mathrm{NA}$ \\
\hline DM & $0.95(0.80-1.14)$ & 0.64 & & $\mathrm{NA}$ & $\mathrm{NA}$ \\
\hline Hypertension & $2.27(0.78-6.64)$ & 0.13 & & $1.35(0.43-4.25)$ & 0.60 \\
\hline Smoking & $0.60(0.20-1.82)$ & 0.37 & & $\mathrm{NA}$ & $\mathrm{NA}$ \\
\hline CKD & $1.43(0.44-4.62)$ & 0.54 & & $\mathrm{NA}$ & $\mathrm{NA}$ \\
\hline PAOD & $2.91(0.78-10.71)$ & 0.11 & & $1.62(0.39-6.77)$ & 0.50 \\
\hline Symptomatic stenosis & $3.48(0.94-12.88)$ & 0.06 & & $2.95(0.68-12.78)$ & 0.14 \\
\hline Antiplatelet therapy* & $1.50(0.49-4.52)$ & 0.47 & & $\mathrm{NA}$ & $\mathrm{NA}$ \\
\hline General anesthesia & $1.48(0.49-4.47)$ & 0.48 & & $\mathrm{NA}$ & $\mathrm{NA}$ \\
\hline Subclinical CAD & $0.57(0.19-1.66)$ & 0.31 & & $\mathrm{NA}$ & $\mathrm{NA}$ \\
\hline
\end{tabular}

$\mathrm{Cl}=$ confidence interval; $\mathrm{OR}=$ odds ratio.

* Previous use of antiplatelet agents regardless of CEA/coronary revascularization. 
ter understanding of the safety and efficacy of CEA in patients with simultaneous significant carotid artery stenosis and subclinical CAD.

\section{References}

1. Aboyans V, Lacroix P: Indications for carotid screening in patients with coronary artery disease. Presse Med 38:977986, 2009

2. Beattie WS, Abdelnaem E, Wijeysundera DN, Buckley DN: A meta-analytic comparison of preoperative stress echocardiography and nuclear scintigraphy imaging. Anesth Analg 102:8-16, 2006

3. Berman DS, Abidov A, Kang X, Hayes SW, Friedman JD, Sciammarella MG, et al: Prognostic validation of a $17-$ segment score derived from a 20-segment score for myocardial perfusion SPECT interpretation. J Nucl Cardiol 11:414-423, 2004

4. Brott T, Adams HP Jr, Olinger CP, Marler JR, Barsan WG, Biller J, et al: Measurements of acute cerebral infarction: a clinical examination scale. Stroke 20:864-870, 1989

5. Brott TG, Halperin JL, Abbara S, Bacharach JM, Barr JD, Bush RL, et al: 2011 ASA/ACCF/AHA/AANN/AANS/ACR/ ASNR/CNS/SAIP/SCAI/SIR/SNIS/SVM/SVS guideline on the management of patients with extracranial carotid and vertebral artery disease. Stroke 42:e464-e540, 2011

6. Brott TG, Hobson RW II, Howard G, Roubin GS, Clark WM, Brooks W, et al: Stenting versus endarterectomy for treatment of carotid-artery stenosis. N Engl J Med 363:11-23, 2010

7. Cohen MC, Siewers AE, Dickens JD Jr, Hill T, Muller JE: Perioperative and long-term prognostic value of dipyridamole Tc-99m sestamibi myocardial tomography in patients evaluated for elective vascular surgery. J Nucl Cardiol 10:464472, 2003

8. Cunningham EJ, Bond R, Mehta Z, Mayberg MR, Warlow CP, Rothwell PM: Long-term durability of carotid endarterectomy for symptomatic stenosis and risk factors for late postoperative stroke. Stroke 33:2658-2663, 2002

9. Fleisher LA, Fleischmann KE, Auerbach AD, Barnason SA, Beckman JA, Bozkurt B, et al: 2014 ACC/AHA guideline on perioperative cardiovascular evaluation and management of patients undergoing noncardiac surgery: a report of the American College of Cardiology/American Heart Association Task Force on practice guidelines. J Am Coll Cardiol 64:e77-e137, 2014

10. Gale CP, Metcalfe E, West RM, Das R, Kilcullen N, Morrell $\mathrm{C}$, et al: An assessment of the concentration-related prognostic value of cardiac troponin I following acute coronary syndrome. Am J Cardiol 108:1259-1265, 2011

11. Galyfos G, Sigala F, Tsioufis K, Bakoyiannis C, Lagoudiannakis E, Manouras A, et al: Postoperative cardiac damage after standardized carotid endarterectomy procedures in lowand high-risk patients. Ann Vasc Surg 27:433-440, 2013

12. Galyfos G, Tsioufis C, Theodorou D, Katsaragakis S, Zografos G, Filis K: Predictive role of stress echocardiography before carotid endarterectomy in patients with coronary artery disease. Echocardiography 32:1087-1093, 2015

13. Gopaldas RR, Chu D, Dao TK, Huh J, LeMaire SA, Lin P, et al: Staged versus synchronous carotid endarterectomy and coronary artery bypass grafting: analysis of 10 -year nationwide outcomes. Ann Thorac Surg 91:1323-1329, 2011

14. Harafuji K, Chikamori T, Kawaguchi S, Obitsu Y, Ito S, Igarashi Y, et al: Value of pharmacologic stress myocardial perfusion imaging for preoperative risk stratification for aortic surgery. Circ J 69:558-563, 2005

15. Illuminati G, Schneider F, Greco C, Mangieri E, Schiariti $\mathrm{M}$, Tanzilli G, et al: Long-term results of a randomized con- trolled trial analyzing the role of systematic pre-operative coronary angiography before elective carotid endarterectomy in patients with asymptomatic coronary artery disease. Eur J Vasc Endovasc Surg 49:366-374, 2015

16. Kim YH, Ahn JM, Park DW, Song HG, Lee JY, Kim WJ, et al: Impact of ischemia-guided revascularization with myocardial perfusion imaging for patients with multivessel coronary disease. J Am Coll Cardiol 60:181-190, 2012

17. Kristensen SD, Knuuti J, Saraste A, Anker S, Bøtker HE, Hert SD, et al: 2014 ESC/ESA Guidelines on non-cardiac surgery: cardiovascular assessment and management: The Joint Task Force on non-cardiac surgery: cardiovascular assessment and management of the European Society of Cardiology (ESC) and the European Society of Anaesthesiology (ESA). Eur Heart J 35:2383-2431, 2014

18. Li Y, Walicki D, Mathiesen C, Jenny D, Li Q, Isayev Y, et al: Strokes after cardiac surgery and relationship to carotid stenosis. Arch Neurol 66:1091-1096, 2009

19. Liapis CD, Bell PR, Mikhailidis D, Sivenius J, Nicolaides A, Fernandes e Fernandes J, et al: ESVS guidelines. Invasive treatment for carotid stenosis: indications, techniques. Eur J Vasc Endovasc Surg 37 (4 Suppl):1-19, 2009

20. North American Symptomatic Carotid Endarterectomy Trial Collaborators: Beneficial effect of carotid endarterectomy in symptomatic patients with high-grade carotid stenosis. $\mathbf{N}$ Engl J Med 325:445-453, 1991

21. Nuotio K, Soinne L, Hänninen H, Saksi J, Tuimala J, Jula A, et al: Life-threatening coronary disease is prevalent in patients with stenosing carotid artery disease. Int J Stroke 10:1217-1223, 2015

22. Padma S, Sundaram PS: Current practice and recommendation for presurgical cardiac evaluation in patients undergoing noncardiac surgeries. World J Nucl Med 13:6-15, 2014

23. Shaw LJ, Eagle KA, Gersh BJ, Miller DD: Meta-analysis of intravenous dipyridamole-thallium-201 imaging (1985 to 1994) and dobutamine echocardiography (1991 to 1994) for risk stratification before vascular surgery. J Am Coll Cardiol 27:787-798, 1996

24. Thygesen K, Alpert JS, Jaffe AS, Simoons ML, Chaitman BR, White HD, et al: Third universal definition of myocardial infarction. Eur Heart J 33:2551-2567, 2012

25. Urbinati S, Di Pasquale G, Andreoli A, Lusa AM, Carini G, Grazi P, et al: Preoperative noninvasive coronary risk stratification in candidates for carotid endarterectomy. Stroke 25:2022-2027, 1994

\section{Disclosures}

The authors report no conflict of interest concerning the materials or methods used in this study or the findings specified in this paper.

\section{Author Contributions}

Conception and design: Cho, H Kwon, Moon, Han. Acquisition of data: Cho, H Kwon, Moon, Han, Lee, SU Kwon, Kang, Choo, TW Kwon. Analysis and interpretation of data: Cho, H Kwon, Moon, Han, Lee, Kim. Drafting the article: Cho, H Kwon, Moon, Han, Lee. Critically revising the article: Cho. Reviewed submitted version of manuscript: all authors. Approved the final version of the manuscript on behalf of all authors: Cho. Statistical analysis: Kim.

\section{Correspondence}

Yong-Pil Cho, Department of Surgery, University of Ulsan College of Medicine and Asan Medical Center, Asanbyeongwon-gil 86, Songpa-gu, Seoul 05505, Republic of Korea. email: ypcho@ amc.seoul.kr. 